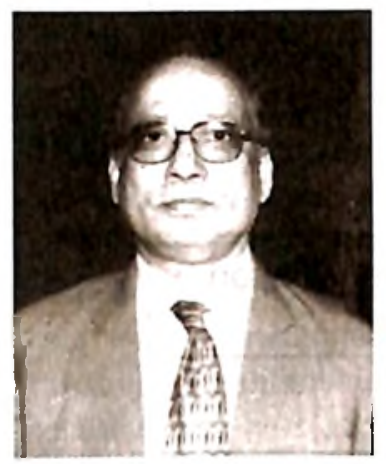

\title{
From Hony. Secretary General's Desk
}

Dear Members,

The National Welding Seminar (NWS-2005) \& exhibition was held at Bhilai from 15th December to 17th December 2005 organized by our IIW Bhilai Branch jointly with SAIL Bhilai Steel Plant. Congratulations to the Managing Committee \& members of the IIW Bhilai Branch for organizing this prestigious event successfully. We also thank the management of Bhilai Steel Plant for their wholehearted support and participation in the Seminar.

During this event we had also organized the Annual Members Assembly on 16th December 2005. A large number of members attended the assembly and participated in the discussion and expressed their valued opinion and suggestion for the growth of the Institute.

We would like to inform you that we have already got applicant ANB status of the International Institute of Welding. Our ANB Governing Body is in the process of appointing Authorized Training Bodies in India. We invite applications from all the Welding Training Institutes to enroll as ATB of the Institute.

AMIIW examinations are being held regularly at different centres and results are also published in time. Continuous efforts are being made to increase students for AMIIW degree Examination. Branches need to focus on enrolling more students by interacting and involving Industries who will be ultimately benefited with the qualified Engineers.

The second convocation of the AMIIW Degree Award Ceremony will be held on 28th February 2006 at 3:30 p.m. at Banquet hall 'Alapan". Peerless Hotel Inn. Prof. Ashoke Ranjan Thakur will deliver the convocational address in this occasion.

I. on behalf of the Central Council, invite all the members with their friends to attend the convocation. We are continuing our intensive efforts to increase the membership and also renew the membership of defaulting members. All the branches need to review the situation and put all our efforts in this respect during this year.

As per decision of the last council the IWJ from April issue will be published from $H Q$. I, on behalf of the Central council, request all the members to help IWJ by way of giving technical papers, advertisements and also valuable suggestions to make the IWJ an International Standard Journal as well as self financing.

The Annual General Meeting of your Institute for the year 2004-2005 will be held on 18th February 2006 at Banquet Hall 'Alapan" Peerless Hotel Inn at 4:30 p.m. All the members of the Institute are cordially invited to attend the AGM of the institute.

With Best Regards

Parimal Biswas 